\title{
COMENTARIO AL ARTÍCULO SOBRE LA EFECTIVIDAD DE TRES IRRIGANTES SOBRE EL NÚMERO DE COLONIAS DE ENTEROCOCCUS FAECALIS EN LA PREPARACIÓN DE CONDUCTOS RADICULARES IN VITRO
}

\author{
COMMENTARY ON THE ARTICLE ON THE EFFECTIVENESS OF THREE IRRIGANTS \\ ON THE NUMBER OF COLONIES OF ENTEROCOCCUS FAECALIS IN THE \\ PREPARATION OF IN VITRO ROOT CANALS
}

\begin{abstract}
Ysabel Osorio ${ }^{1, a}$
Señor editor, en el artículo titulado Efectividad de tres irrigantes sobre el número de colonias de enterococcus faecalis en la preparación de conductos radiculares in vitro realizado por Jorge AlamoPalomino, Seber A. Guardia-Huamaní, Román Mendoza-Lupuche, Libia M. Guerra-Barrera ( ${ }^{1}$.

Considero oportuno resaltar lo mencionado en el artículo respecto a que la eliminación de microorganismos es uno de los pasos más importantes del tratamiento endodóntico, siendo las bacterias facultativas, como Enterococcus faecalis las que han sido relacionadas a las patologías de los canales radiculares y que también poseen grandes frecuencias en casos de lesiones periapicales ${ }^{(2,3)}$. El empleo de substancias químicas durante la preparación químicamecánica del canal radicular asume especial importancia en la desinfección y la limpieza del sistema de canales radiculares. Por su parte, las soluciones empleadas en los procedimientos de irrigación-aspiración desempeñan una acción física importante en la remoción de detritus y en la reducción del número de bacterias existentes en el interior del conducto ${ }^{(4)}$.

Siendo el hipoclorito de sodio elirrigante más utilizado en endodoncia, para poder comprender como actúa en el conducto radicular tendríamos que pensar que cuando añadimos $\mathrm{NaOCl}$ a agua obtenemos la reacción $\mathrm{NaOH}+\mathrm{OHCl}$, este acido hipocloroso en una solución acuosa que se va a disociar parcialmente en

Se define clorina disponible, como la suma de ácido hipocloroso y el anión hipoclorito. El ácido hipocloroso es la parte activa y responsable de la capacidad antibacteriana. Este acido hipocloroso ejerce su efecto oxidando los grupos sulfihidrilos de los sistemas enzimáticos de las bacterias produciendo alternaciones en las reacciones metabólicas y finalmente la muerte de la bacteria ${ }^{(5-7)}$.

Referente a la concentración de Hipoclorito de sodio efectivo para la eliminación de colonia de $E$. faecalis Harrison y Cols. demostraron que la disolución de $\mathrm{NaOCl}$ disminuye significativamente la propiedad para disolver tejido necrótico. Su concentración al $2.5 \%$ fue tan solo un tercio efectiva en comparación con una concentración de 5.25\% y como también Gómez y Cols. demostraron que el $\mathrm{NaOCl}$ al $5.25 \%$ mata $E$. faecalis en 30 segundos mientras que en concentraciones más bajas requiere de 10 a 30 minutos. Concordando que el uso de Hipoclorito de sodio al $5.25 \%$ según la literatura es altamente efectiva , pero uno de los puntos que no se tomó en cuenta es el tiempo en eliminar el E. faecalis; a pesar de las desventajas que trae consigo; de ser citotóxico, irritante, falta de capacidad de penetrar porciones estrechas del sistema de conductos, ser ineficientes en la remoción del ladillo dentinario lo cual es fundamental para la eliminación de microflora y toxinas; aun así; se puede llegar a la conclusión que sigue siendo el agente irrigante con mayor efectividad del E. faecalis.
\end{abstract} $\mathrm{OCl}$ (anión hipoclorito). 
Podemos agregar que Yamada et al. concluyen que la solución más efectiva al final para la limpieza y remoción del lodo dentinario fue de $10 \mathrm{ml}$ de EDTA al $17 \%$ seguida de $10 \mathrm{ml}$ de $\mathrm{NaOCl}$ a $5.25 \%{ }^{(8)}$.

Como conclusión del presente artículo se recomendaría que una efectiva técnica de irrigación es un requisito indispensable para el éxito del tratamiento endodóntico.

Los avances de la tecnología en la última década han llevado a la creación de nuevos sistemas de irrigación que permiten tener una amplia variedad de mecanismos para potencializar la acción de los irrigantes, así como un mejor entendimiento de sus propiedades químicas, evitando, con su combinación reducir el tiempo de acción del más importante de ellos que son el hipoclorito de sodio, y en consecuencia la inactivación del gas clorina, responsable de la desinfección efectiva y la disolución del tejido orgánico intrarradicular.

Asimismo, la temperatura va a ser un factor importante que va a ayudar a mejorar las propiedades del hipoclorito de sodio. El aumento de dicha temperatura de la solución de hipoclorito de sodio disminuye su tensión superficial permitiendo una mayor penetración en el conducto. Entonces cuando se aumenta la temperatura de una solución de $\mathrm{NaOCl}$ al $2.5 \%$ hasta $37^{\circ} \mathrm{C}$ se va a obtener las mismas propiedades de limpieza que el $\mathrm{NaOCl}$ al $5.25 \%$, pero con menos efectos citotóxicos ${ }^{(9,10)}$.

En la actualidad hay nuevas técnicas de irrigación tales como, sistema endoactivador, activador pasivo de ultrasonido, desinfección fotoactivada (PAD), gas ozono y EndoVac, que serán complementarias a las técnicas de irrigación existentes ${ }^{(11)}$.

El uso de irrigación con el sistema de activación ultrasónica pasiva para la eliminación de E. faecalis, al vibrar dentro del conducto va ayudar al irrigante a penetrar de forma más efectiva a través de lostúbulos dentinarios ${ }^{(12)}$.
Además, el uso de ozono ha sido propuesto para la desinfección para el conducto radicular, sin embargo; con una debida protección en cuanto a la exposición del gas tanto del paciente como del profesional y el personal asistente ${ }^{(13)}$

\section{REFERENCIAS BIBLIOGRÁFICAS}

1.Alamo-Palomino J, Guardia-Huamaní S, Mendoza- Lupuche R, Guerra-Barrera L. Efectividad de tres irrigantes sobre el número de colonias de enterococcus faecalis en la preparación de conductos radiculares in vitro. Revista Kiru. 2015 ene-jun; 12(1):8-12.

2.Engström B. The significance of enterococci in root canal treatment. Odont Revy. 1964; 15:87-105.

3. Molander A, Reit C, Dahlén G, Kvist T. Microbiological status of root-filled teeth with periodontitis. Int Endod J. 1998; 31:17.

4.Amada R. Eficacia antimicrobiana de microdacyn 60, hipoclorito de sodio al 5,25\% y Mtad contra Enterococcus faecalis. (Tesis de Maestría). Universidad Autonóma de Nuevo León; 2012

5.Baumgartner JC CP. Efficacy of several concentrations of sodium hypochlorite for root canal irrigations. J Endod. 1992; 18:605-12.

6. Vianna ME HH, Conrads G, Gomes BP. In vivo evaluation of microbial reduction after chemo-mechanical preparation of human root canals containing necrotic pulp tissue. Int Endod J. 2006; 39:484-92.

7. Christensen CE MS, Eleazer P. Effect of lowering the $\mathrm{pH}$ of sodium hypochlorite on dissolving tissue in vitro. J Endod. 2008; 34:449-52.

8.Violich DR, Chandler NP. The smear layer in endodonticreview. Int endod J 2010; 43:2-15.

9. Asuero MM, Ordoñez AF, Tinjacá V. Comparación de tres soluciones irrigantes utilizadas en endodoncia. Rev.Odont Javer 2004; 13:45-46.

10. Sirts G, Waltimo T, Schaetzle M, Zehnder M, the effects of temperature on Sodium Hipochlorite, short-term stability, pulp dissolution capacity, and antimicrobial efficacy. J endod 2005; 31(9):669-671.

11. http://www.endodoncia-sae.com.ar-/info articulos02.htm

12. Vander Sluis LWM, Versluis M, Wu MK, Wesselink PR. Passive ultrasonic irrigation off the root canal: arriview off the literature. Int endod J 2007; 40:415-426.

13.Hülsmann M, Rödig T, Nordmeyer S. Complicatons during root canal irrigation. Endod Top 2009; 16:27-63. 